\title{
A diversidade em sala de aula e a relação professor-aluno'
}

\section{Diversity in the classroom and the teacher-student relationship}

\author{
Altemir José Gonçalves BARBOSA² \\ Renata Araújo CAMPOS ${ }^{3}$ \\ Tássia Azevedo VALENTIM ${ }^{3}$
}

\begin{abstract}
Resumo
O presente estudo teve como objetivo identificar as percepções de professores quanto à relação professor-aluno, a partir da aplicação da Escala de Relacionamento Professor-Aluno, versão reduzida e traduzida da Student-Teacher Relationship Scale, relacionando seus domínios a características dos discentes, no que tange às variáveis necessidade educacional especial, sexo, cor/raça, série e idade. Na pesquisa, 21 professoras regentes de seis escolas públicas da cidade de Juiz de Fora, no estado de Minas Gerais, avaliaram a relação que mantêm com todos os discentes de suas turmas, perfazendo um total de 495 escalas referentes a estudantes de salas-alvo, do primeiro ao quinto ano do Ensino Fundamental. Constatou-se que a relação professor-aluno é mais conflituosa e menos positiva quando se trata de discentes do sexo masculino e com necessidade educacional especial. Observou-se uma relação mais positiva com estudantes nos anos iniciais de escolarização, e mais negativa quanto mais velho fosse o aluno. Estudos adicionais são recomendados.
\end{abstract}

Unitermos: Ambiente da sala de aula. Desenvolvimento psicossocial. Interação professor-aluno.

\begin{abstract}
This study aimed to identify teachers' perceptions of the teacher-student relationship, based on the application of an abridged, translated version of the Student-Teacher Relationship Scale, linking their factors to the characteristics of students in respect of the following variables: specialeducational needs, gender, color/race, grade and age range. Regents teachers ( $n=21$ ) from six public schools in the city of Juiz de Fora (Brazil) evaluated the relationship they have with all students in their classes, amounting to a total of 495 scales related to students in the 21 rooms targeted, in the first to fifth years of elementary school. It was found that the teacher-student relationship is more confrontational and less positive when it comes to male students and those with special educational needs. There is a more positive relationship with students in the early years of school, which becomes more negative the older the student becomes. Additional research is recommended.
\end{abstract}

Uniterms: Diversity in the classroom. Psychosocial development. Teacher-student interaction.

A relação professor-aluno é fundamental para o desenvolvimento integral das crianças. A partir da relação com os docentes, ela adquire conhecimentos para todo o curso de vida e tem suas capacidades psicossociais promovidas.
Baker (2006) destaca que a relação professor-aluno é necessária para o engajamento das crianças na aprendizagem; é, também, a base para o desenvolvimento de crenças adaptativas sobre si mesmo e sobre o mundo social, e para a aquisição de comportamentos

\section{ขัข}

- Apoio: Fundação de Amparo à Pesquisa de Estado de Minas Gerais.

2 Universidade Federal de Juiz de Fora, Programa de Pós-Graduação em Psicologia, Departamento de Psicologia. R. José Lourenço Kelmer, s/n., Campus Universitário, São Pedro, 36036-330, Juiz de Fora, MG, Brasil. Correspondência para/Correspondence to: A.J.G. BARBOSA. E-mail: <altgonc@uol.com.br>.

3 Psicólogas. Juiz de Fora, MG, Brasil. 
e competências autorreguladoras e socioemocionais, essenciais no ambiente escolar. A relação com um adulto, se positiva, constitui por si mesma um fator de proteção e, ainda, promove fatores protetores, tais como autoeficácia, autoestima e desenvolvimento moral. 0 educador deve ser um suporte e guia para a aprendizagem, bem como um potencial mediador e moderador de um processo motivacional significativo (Baker, 2006; Birch \& Ladd, 1997).

Para Baker (2006), a qualidade da relação professor-aluno é um forte indicador de adaptação escolar, especialmente para crianças que apresentam problemas comportamentais em sala de aula. Birch e Ladd (1997) também consideram que o relacionamento dos discentes com os docentes é consideravelmente associado a um positivo ajustamento escolar. Segundo Baker (2006), essa relação, quando positiva, está associada a uma variedade de consequências escolares importantes, como o sucesso escolar e a confiança dos alunos em relação a suas capacidades, atitudes e motivações escolares. Birch e Ladd (1997) acrescentam que crianças que apresentam uma relação mais próxima com o professor podem perceber o ambiente escolar como um apoio/ suporte, desenvolvendo atitudes positivas quanto à escola; podem expressar seus sentimentos e preocupações e, por essa razão, solicitar apropriadamente ajuda e orientação em sua tentativa de adaptar-se ao ambiente escolar. Essa relação de apoio entre professor e aluno pode, portanto, habilitar as crianças para se tornarem autodirigidas e participantes responsáveis na sala de aula.

Uma relação positiva com os alunos pode prevenir problemas disciplinares no ambiente escolar e, ainda, o stress do professor e o burnout, bem como fomentar o desenvolvimento profissional do docente (Fraser \& Walberg, 2005; Wubbels, 2005). Quando negativa, a relação professor-aluno pode se associar à pobreza acadêmica e social, à evasão escolar, a uma menor cooperação em sala de aula, a atitudes escolares negativas, a um comportamento menos autodirigido, ao isolamento social, a sentimentos de solidão e a um menor engajamento (Baker, 2006; Birch \& Ladd, 1997).

A relação professor-aluno também afeta outras interações que os estudantes mantêm na escola. Robertson, Chamberlain e Kasari (2003) destacam que a relação com os professores afeta o status social dos alu-

454 nos na classe.
Em anos recentes, a escola pública no Brasil mudou substancialmente a configuração social da sala de aula. Antes, o corpo discente era bastante homogêneo, composto majoritariamente por estudantes brancos, de níveis socioeconômicos privilegiados e sem necessidades educacionais especiais. Hoje, políticas públicas que priorizam inclusão escolar de alunos com Necessidade Educacional Especial (NEE), que atrelam complementação de renda à frequência escolar e que buscam combater a evasão e aumentar a escolaridade da população fizeram com que, forçosamente, a diversidade passasse a ser característica marcante das salas de aula. Assim, lidar com a diversidade de estudantes em sala de aula, seja ela referente à presença de NEE, à idade, ao sexo e/ou à cor/raça, que são focos do presente estudo, passou a ser um imperativo e um desafio para os educadores.

As interações entre educadores e estudantes com NEE em salas de aula regulares são fundamentais para o desenvolvimento socioemocional dessas crianças. Convivendo com seus pares e com professores, elas aprendem por meio das experiências e das diferenças individuais, ampliando suas oportunidades de obtenção de conhecimento, competências, habilidades e valores. Esse é um dos propósitos da inclusão escolar, assegurada pela Declaração de Salamanca (Organização das Nações Unidas para a Educação, a Ciência e a Cultura, 1994).

Para Katz e Mirenda (2002), existem evidências de que as interações estabelecidas em sala de aula entre os alunos com NEE, os pares e os professores são extremamente relevantes para o desenvolvimento de aspectos comportamentais, da comunicação e de habilidades sociais, bem como para o desempenho acadêmico. Trata-se de um dos benefícios sociais da inclusão escolar. Assim, a educação inclusiva pode gerar muitos benefícios sociais para todos os alunos, com e sem NEE, especialmente se as escolas contarem com ambientes de aprendizagem e sociais promotores de suporte.

Com relação ao sexo, vários estudos evidenciam que as relações entre professores e discentes são mais conflituosas e menos positivas quando se trata de estudantes do sexo masculino (Baker, 2006; Birch \& Ladd, 1997; Brok \& Levy, 2005; Kesner, 2000; C. Murray, K.M. Murray \& Waas, 2008). Para Baker (2006), as meninas se atentam mais ao meio social e diversificam mais seus relacionamentos. Esses fatores podem beneficiar o seu 
desenvolvimento emocional e favorecer a relação que estabelecem com o professor (Baker, 2006). Gera-se, assim, um círculo frutuoso.

Para os professores, as meninas têm atitudes mais positivas em sala de aula e são mais cooperativas que os meninos (Birch \& Ladd, 1997). Eles apresentam comportamentos mais agressivos e têm menos maturidade ao ingressar na escola; elas se ajustam melhor ao ambiente escolar (Baker, 2006; Kesner, 2000).

Os estudos que abordam as diferenças entre 0 sexo masculino e o feminino em ambiente escolar têm priorizado variáveis acadêmicas, como desempenho escolar, em detrimento de questões afetivo-emocionais, como a relação professor-aluno (Carvalho, 2003, 2004a, 2004b, 2005; Dal'Igna, 2007; Henriques, 2002). Dal'Igna (2007), por exemplo, analisa as diferenças de desempenho entre eles. Para a autora, os meninos são mais desatentos, inseguros, agressivos, desinteressados e distraídos, enquanto as meninas apresentam dificuldades justificadas por sua (in)capacidade cognitiva. Quanto à adaptação escolar, as meninas, por serem bem-comportadas, organizadas, disciplinadas, obedientes e caprichosas, apresentam melhor ajustamento escolar. Os meninos, por sua vez, são mais indisciplinados, agitados e desorganizados.

Processo semelhante ocorre no que se refere à cor/raça no meio escolar. A maioria dos estudos que abordam tais variáveis analisa as desigualdades étnico/raciais expressas em termos da escolaridade das crianças e jovens, enfatizando as diferenças de desempenho escolar, evasão e repetência (Carvalho, 2003, 2004a, 2004b, 2005; Henriques, 2002; Kesner, 2000; Munanga, 2005; Patto, 1990).

Kesner (2000) alerta para a prevalência de variáveis puramente acadêmicas e, consequentemente, para a exclusão da relação afetiva nas pesquisas sobre a interação professor-aluno. Destaca que essa dimensão é de suma importância e que são necessários estudos que considerem a cor/raça e o sexo em ambiente escolar, pois, por um lado, a grande maioria dos educadores do ensino fundamental é branca (Kesner, 2000) e do sexo feminino (Carvalho, 2003) e, por outro lado, um número expressivo de alunos em classes de reforço, repetentes e que evadem são pretos ou pardos e do sexo masculino (Carvalho, 2003, 2004a, 2004b, 2005; Henriques, 2002).
Carvalho (2004b; 2005) verificou que é significativamente maior o número de alunos brancos e do sexo feminino elogiados pelo docente. A autora também destaca o predomínio de meninos com problemas de disciplina, sendo essa última variável não significativa quando comparada à cor/raça do discente.

Murray et al. (2008) averiguaram que crianças com origens socioeconômicas mais favorecidas estabelecem maior proximidade e uma relação menos conflituosa com os professores do que estudantes não brancos. Há evidências de que a relação professor-aluno é mais positiva quando ambos são da mesma origem étnico-racial.

Henriques (2002) constatou ser expressivamente pior a distribuição da escolaridade para negros, padrão que se mantém estável entre as gerações, mesmo com a melhoria nos níveis médios de escolaridade de brancos e negros ao longo do século. Ele infere que o impedimento ao desenvolvimento das potencialidades e ao progresso social da população negra é decorrente da significativa desigualdade racial brasileira, atrelada a formas sutis de discriminação racial.

Resultados análogos foram encontrados nas pesquisas de Carvalho (2003; 2004a; 2004b; 2005). A autora salienta que os maiores problemas de fracasso escolar referem-se ao grupo de alunos negros do sexo masculino, como indicam as estatísticas educacionais brasileiras há algumas décadas. Mas destaca"... a necessidade de investigar as interações entre professores, professoras, alunos e alunas, sempre perpassadas por um conjunto de desigualdades sociais de raça, classe e sexo" (Carvalho, 2004a, p.251). Patto (1990), já há bastante tempo, sinalizava o peso do racismo na produção do fracasso escolar.

Cabe ressaltar que o conceito de raça adotado no estudo de Carvalho (2004a; 2004b; 2005) refere-se à "raça social", não se tratando de um dado biológico, mas sim de um constructo social. Para a autora, a classificação racial no Brasil é fluida e variável, sendo possível ultrapassar a linha de cor em decorrência da combinação entre aparência (características fenotípicas, como cor de pele e cabelo), ascendência e status social. Há uma subjetividade na classificação por cor: ao mesmo tempo que a raça negra seria atribuída a crianças com dificuldades de aprendizagem, os problemas escolares (de aprendizagem ou disciplina) podem se desenvolver 
com maior frequência em crianças que se autoclassificam ou são percebidas como negras.

De acordo com Boardman (2004), modelos de estudo que utilizam perspectivas socioculturais, ou seja, baseados no pressuposto de que as crianças aprendem pela participação em contextos sociais, têm sido utilizados com o propósito de averiguar a maneira pela qual os alunos se desenvolvem social e academicamente, ao invés de focalizarem as diferenças individuais.

Coll e Solé (1995) afirmam que, historicamente, o estudo da interação professor-aluno passou por várias etapas, com métodos e objetos de pesquisa distintos. A eficácia docente tem sido abordada de maneiras diferenciadas no decorrer da história. Os estudos iniciais visavam identificar as características pessoais dos professores como responsáveis por essa eficácia, tendo tais investigações sofrido fervorosas objeções. Num momento posterior, procurou-se identificar métodos de ensino eficazes com o mesmo intuito, deparando-se com dificuldades de ordem teórica e metodológica. Retomou-se, então, o valor do que ocorre realmente em sala de aula, ou seja, a interação entre professor e alunos, demandando o uso de instrumentos mais eficazes.

Um procedimento bastante usado em estudos sobre a relação professor-aluno consiste em aplicar instrumentos de autopreenchimento, especialmente escalas tipo Likert, para que os docentes avaliem sua relação com os discentes. A Student-Teacher Relationship Scale (STRS) (Pianta, 2001) é um exemplo disso.

Para Birch e Ladd (1997), a perspectiva do professor fornece informações valiosas que enriquecem a compreensão da relação que mantém com a criança no ambiente escolar. Para os autores, as percepções sobre a qualidade da relação docente/discente estão associadas ao desempenho das crianças nas atividades acadêmicas, a seu ajustamento socioemocional, à evasão escolar, aos relatos dos professores acerca da variabilidade da adaptação escolar.

O objetivo geral deste estudo foi identificar as percepções de professores quanto à relação professor-aluno, considerando a diversidade de discentes presentes em sala de aula nas escolas públicas. Especificamente, os objetivos foram: caracterizar a relação pro-

456 fessor-aluno positiva total; descrever os níveis de afini- dade e de conflito na relação professor-aluno; e associar relação positiva total, afinidade e conflito às características dos discentes, no que tange às variáveis NEE, sexo, cor/raça, série e idade.

\section{Método}

\section{Participantes}

Participaram deste estudo 21 professoras regentes de seis escolas públicas da cidade de Juiz de Fora (MG). Elas lecionavam em salas do primeiro ao quinto ano do ensino fundamental, tendo cada uma delas avaliado a relação que mantinha com todos os discentes de sua turma. Foram desprezados os instrumentos que apresentavam problemas no preenchimento, restando 495 medidas respondidas pelas docentes.

A idade Média (M) das docentes foi igual a 45,5 (Desvio-Padrão - DP=9,89). Classificaram-se como brancas (70\%; n=14) ou pardas (30\%; n=3). A experiência de ensino, em anos, variou de 1 a $36(M=19,67 ; D P=9,42)$. No que se refere à formação acadêmica das participantes, foi constatado que duas $(9,5 \%)$ delas completaram o Ensino Médio (Magistério), cinco (23,8\%) possuíam Educação Superior (Graduação), 13 (61,9\%) cursaram Pós-Graduação/Especialização, e uma (4,7\%) tinha Mestrado. Cabe ressaltar que a classificação de cor/raça abordada no presente estudo foi a do Instituto Brasileiro de Geografia e Estatística (IBGE): indígena; preto(a); pardo(a); amarelo(a); e branco(a).

\section{Instrumento}

Para avaliar as percepções das docentes quanto à relação professor-aluno, foi utilizada a Escala de Relacionamento Professor-Aluno (ERPA). Trata-se de uma versão em português da Student-Teacher Relationship Scale: Short Form, desenvolvida por Pianta (2001) e disponibilizada pelo National Institute of Child Health and Human Development (2005). É uma versão reduzida da STRS, que usa 30 itens para avaliar a percepção dos professores sobre seu relacionamento com os estudantes.

A ERPA possui 15 itens com cinco pontos de resposta, que vão de "com certeza não se aplica" a "com certeza se aplica". Sete itens representam relações 
"adequadas" entre docentes e discentes e constituem o fator afinidade; os demais refletem interações disfuncionais e compõem o fator conflito. A relação positiva total é calculada a partir da soma de todos os itens. Nesse caso, os itens do fator conflito devem ser espelhados antes de serem usados. O possível alcance da pontuação é de 15 a 75, com as maiores pontuações indicando uma melhor relação entre o educador e a criança.

O professor deve preencher uma medida para cada um de seus alunos. Assim, se ele ministrar aula para uma turma com 30 estudantes, preencherá essa quantidade de cópias do instrumento.

A ERPA não possui indicadores psicométricos para a realidade brasileira. Ressalta-se, no entanto, que ela passou por tradução/retrotradução e por um estudo piloto para analisar a adequação dos itens e dos fatores para o contexto brasileiro (Barbosa, Campos \& Valentim, 2007), para se chegar à versão que foi utilizada nesta investigação. Ainda assim, cumpre antecipar que essa é uma limitação deste estudo.

\section{Procedimentos}

O estudo foi aprovado pelo Comitê de Ética da Universidade Federal de Juiz de Fora, sob o protocolo $n^{\circ}$ 256/2006, em 21 de setembro de 2006. Os participantes assinaram um Termo de Consentimento Livre e Esclarecido antes de sua inclusão na amostra. A coleta de dados ocorreu na escola, em local que assegurasse a confidencialidade.

Os dados foram tratados quantitativamente, adotando-se um nível de significância de 0,05 por convenção. As características dos estudantes descritas pelas professoras foram consideradas variáveis independentes, e a percepção delas quanto à relação positiva total, ao conflito e à afinidade nas interações professor-aluno constituiu as variáveis dependentes.

\section{Resultados}

A Tabela 1 apresenta as características dos estudantes que foram alvo das respostas dadas pelas 21 professoras. Destaca-se que o "n"e o " $\mathrm{N}$ " correspondem às cópias dos instrumentos preenchidos por essas docentes. Isso ocorre, também, na outra tabela apresentada neste estudo.
Tabela 1. Caracterização do corpo discente na percepção das docentes

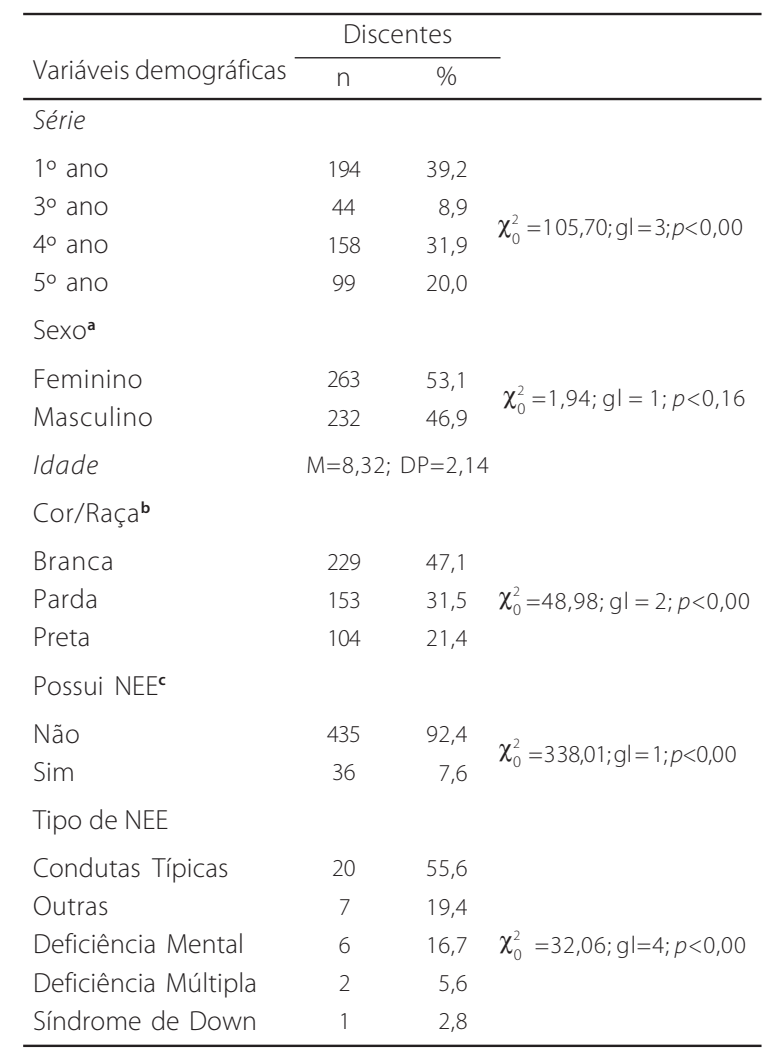

${ }^{a} N=495 ;{ }^{b} N=486 ;{ }^{c} N=471 ; M:$ média; DP: desvio-padrão.

Verificou-se uma proporção equivalente de estudantes do sexo feminino e masculino. Preponderaram os estudantes classificados pelas educadoras como brancos sem NEE, cursando o primeiro ano do ensino fundamental. Quanto ao tipo de NEE, predominaram condutas típicas.

No geral, ainda que a ERPA não possua ponto de corte, é possível afirmar que, do ponto de vista das docentes, a relação professor-aluno foi bastante positiva, pois a média foi de 66,36 (DP=9,34), sendo o escore mínimo igual a 30 e o máximo igual a 75. É preciso reiterar que o escore da relação positiva total mensurada pela escala poderia variar entre 15 e 75. Mais de 75,0\% dos escores estão agrupados no intervalo que vai de 60 a 75. Consequentemente, foram observados escores elevados de afinidade, com média de 31,23 ( $D P=4,36)$, sendo o escore mínimo igual a 14 e o máximo igual a 35. Foram encontrados escores baixos para conflito, com média de 12,87 (DP=6,80), e escore mínimo igual a 8 e máximo igual a 40. 
Constatou-se que, no ponto de vista das docentes, há mais afinidade com as alunas e mais conflito com os alunos (Tabela 2). Com relação à cor/raça, não foi observada diferença significativa em nenhuma das medidas. A relação professor-aluno foi caracterizada por mais conflito e menor afinidade quando o estudante possui NEE.

Quando se considerou a variável série, constatou-se diferença significativa tanto para afinidade quanto para conflito. Ao empregar o teste $U$ de Mann-Whitney para comparar pares de anos escolares, verificaram-se diferenças na percepção das professoras para afinidade nas seguintes comparações: primeiro e terceiro $\left(U_{0}=1685,00 ; p<0,00\right)$; primeiro e quarto $\left(U_{0}=12282,00 ; p<0,00\right)$; primeiro e quinto $\left(U_{0}=5873,50\right.$; $p<0,00)$; terceiro e quarto $\left(U_{0}=2156,00 ; p<0,00\right)$; terceiro e quinto $\left(U_{0}=1496,00 ; p<0,00\right)$. Só não foi observada diferença entre o quarto e o quinto ano $\left(U_{0}=7253,00\right.$; $p=0,32$ ). Assim, é possível afirmar que a afinidade é maior com os estudantes do primeiro ano e menor com os alunos do terceiro ano.

No caso do conflito, observou-se diferença somente entre o primeiro e o quinto ano $\left(U_{0}=7202,00\right.$; $p<0,00)$ e entre o quarto e o quinto $\left(U_{0}=6590,00 ; p<0,05\right)$. Evidentemente, não foram verificadas diferenças significativas ao comparar os seguintes anos escolares: primeiro e terceiro $\left(U_{0}=3993,50 ; p=0,49\right)$; primeiro e quarto $\left(U_{0}=14106,00 ; p=0,18\right)$; terceiro e quarto $\left(U_{0}=3336,50\right.$; $p=0,67)$; e terceiro e quinto $\left(U_{0}=1778,00 ; p=0,08\right)$.

Ao avaliar os resultados referentes à relação positiva total do educador com a criança, verificaram-se diferenças nas variáveis sexo, NEE e séries. Para essa última variável, o teste $U$ de Mann-Whitney revelou diferenças entre os seguintes anos escolares: primeiro e terceiro $\left(U_{0}=2550,50 ; p<0,00\right)$; primeiro e quarto $\left(U_{0}=12078,00\right.$; $p<0,00)$; e primeiro e quinto $\left(U_{0}=6232,50 ; p<0,00\right)$. Nas outras três comparações, isto é, terceiro e quarto $\left(U_{0}=2930,50 ; p=0,11\right)$, terceiro e quinto $\left(U_{0}=2128,50\right.$;

Tabela 2.Percepção das docentes quanto à relação professor-aluno, de acordo com as características demográficas dos discentes

\begin{tabular}{|c|c|c|c|c|c|c|}
\hline \multirow{2}{*}{ Variáveis } & \multicolumn{2}{|c|}{ Conflito } & \multicolumn{2}{|c|}{ Afinidade } & \multicolumn{2}{|c|}{ Total } \\
\hline & M & DP & M & $\mathrm{DP}$ & M & DP \\
\hline \multicolumn{7}{|l|}{ Sexo } \\
\hline Feminino & 11,55 & 5,47 & 31,99 & 3,85 & 68,44 & 7,29 \\
\hline Masculino & 14,44 & 7,82 & 30,39 & 4,73 & 64,01 & 10,77 \\
\hline Totala & 12,91 & 6,83 & 31,24 & 4,35 & 66,36 & 9,34 \\
\hline U de Mann-Whitney & \multicolumn{2}{|c|}{$U_{\circ}=24199,00 ; p<0,00$} & \multicolumn{2}{|c|}{$U_{0}=24421,00 ; p<0,00$} & \multicolumn{2}{|c|}{$U_{\circ}=23729,00 ; p<0,00$} \\
\hline \multicolumn{7}{|l|}{ Cor/Raça } \\
\hline Preta & 12,71 & 6,90 & 30,11 & 5,60 & 65,40 & 10,41 \\
\hline Parda & 13,41 & 7,16 & 31,39 & 3,95 & 65,98 & 9,91 \\
\hline Branca & 12,63 & 6,57 & 31,73 & 3,80 & 67,10 & 8,40 \\
\hline Total ${ }^{\mathbf{b}}$ & 12,93 & 6,85 & 31,27 & 4,32 & 66,38 & 9,35 \\
\hline Kruskal-Wallis & \multicolumn{2}{|c|}{$\chi_{0}^{2}=1,32 ; g l=2 ; p=0,51$} & \multicolumn{2}{|c|}{$\chi_{0}^{2}=2,80 ; g l=2 ; p=0,25$} & \multicolumn{2}{|c|}{$\chi_{0}^{2}=0,89 ; g \mid=2 ; p=0,64$} \\
\hline \multicolumn{7}{|l|}{ NEE } \\
\hline Sim & 21,19 & 8,89 & 29,42 & 3,80 & 56,23 & 10,31 \\
\hline Não & 12,18 & 6,18 & 31,44 & 4,38 & 67,26 & 8,86 \\
\hline Totalc & 12,87 & 6,80 & 31,23 & 4,36 & 66,42 & 9,43 \\
\hline U de Mann-Whitney & \multicolumn{2}{|c|}{$U_{\circ}=3362,00 ; p<0,00$} & \multicolumn{2}{|c|}{$U_{0}=4841,00 ; p<0,00$} & \multicolumn{2}{|c|}{$U_{0}=3064,00 ; p<0,00$} \\
\hline \multicolumn{7}{|l|}{ Séries } \\
\hline $1^{\circ}$ ano & 11,53 & 5,46 & 32,90 & 2,72 & 69,37 & 7,00 \\
\hline $3^{\circ}$ ano & 11,95 & 6,12 & 27,50 & 5,42 & 63,55 & 9,31 \\
\hline $4^{\circ}$ ano & 13,27 & 6,75 & 30,79 & 4,69 & 65,51 & 9,52 \\
\hline $5^{\circ}$ ano & 15,25 & 8,68 & 30,34 & 4,52 & 63,09 & 11,27 \\
\hline Totald & 12,87 & 6,80 & 31,23 & 4,36 & 66,36 & 9,34 \\
\hline Kruskal-Wallis & \multicolumn{2}{|c|}{$\chi_{0}^{2}=12,75 ; g l=3 ; p=0,01$} & \multicolumn{2}{|c|}{$\chi_{0}^{2}=53,84 ; g l=3 ; p=0,00$} & \multicolumn{2}{|c|}{$\chi_{0}^{2}=33,85 ; g l=3 ; p=0,00$} \\
\hline
\end{tabular}

$458{ }^{a} \mathrm{~N}=495 ;{ }^{\mathbf{b}} \mathrm{N}=486 ;{ }^{\mathbf{c}} \mathrm{N}=471 ;{ }^{\mathbf{d}} \mathrm{N}=495 ; \mathrm{M}:$ média; DP: desvio-padrão. 
$p=0,83)$ e quarto e quinto $\left(U_{0}=6851,50 ; p=0,09\right)$, não ocorreram diferenças estatisticamente significativas. Em síntese, os escores da relação positiva total entre professor e estudantes são mais negativos quando o aluno pertence ao sexo masculino e tem NEE. Além disso, a relação é mais positiva com os estudantes do primeiro ano.

Ao correlacionar a variável idade com os domínios medidos pela ERPA, constataram-se correlações negativas significativas com relação positiva total $\left(r_{\text {so }}=-0,30 ; p<0,00\right)$ e com afinidade $\left(r_{\text {so }}=-0,24 ; p<0,00\right)$, bem como correlação positiva com conflito $\left(r_{\text {so }}=0,24 ; p<0,00\right)$. Ainda que as associações sejam fracas, é possível afirmar que a relação professor-aluno tende a ser mais negativa com estudantes mais velhos, ou seja, mais conflituosa e menos afetiva.

\section{Discussão}

Apesar de as docentes terem avaliado a relação professor-aluno como positiva, afetuosa e pouco conflituosa, o cenário não tende a ser tão positivo ao se considerar o sexo, a idade e a presença de NEE. Os resultados obtidos corroboram a literatura (Baker, 2006; Birch \& Ladd, 1997; Brok \& Levy, 2005; Kesner, 2000; Murray et al., 2008) ao evidenciar que a relação professor-aluno é mais conflituosa e menos positiva quando se trata de discentes do sexo masculino. Assim, a afinidade é maior com as alunas.

Pôde-se observar, também, que a relação professor-aluno é mais negativa, mais conflituosa e menos afetuosa se o estudante possuir NEE. Esses resultados são consistentes com os citados por Silva e Aranha (2005), isto é, as interações com tais estudantes são mais negativas e corretivas. As autoras sugerem, porém, que estão ocorrendo avanços na interação professora-aluno com NEE. Identificaram, na pesquisa, que as docentes propiciaram maior espaço de participação aos estudantes com deficiência e iniciaram mais interações com os alunos deficientes do que com os demais discentes das duas turmas pesquisadas.

Uma análise superficial tenderia a afirmar que os resultados de Silva e Aranha (2005) são discrepantes dos obtidos na pesquisa aqui descrita. Cabe, entretanto, ressaltar que as autoras avaliaram a relação professor- -aluno considerando constructos distintos e com estratégias diferentes. É preciso destacar, sobretudo, que os estudantes com NEE observados pelas autoras eram todos com deficiências enquanto, no presente estudo, predominaram casos de condutas típicas.

As condutas típicas externalizantes constituem um desafio para os docentes, pois, de acordo com o Ministério da Educação (Brasil, 2002, p.8), abrangem quadros que apresentam comportamentos como "agredir, faltar com a verdade, roubar, gritar, falar ininterruptamente, locomover-se o tempo todo etc.". Buyse, Verschueren, Doumen, Damme e Maes (2007) afirmam que, em muitos estudos, tanto os comportamentos externalizantes quanto os internalizantes colocam em risco a qualidade da relação com o docente. Baker (2006) destaca que comportamentos externalizantes se associam mais comumente a uma relação negativa entre o professor e o aluno.

No caso da variável cor/raça, ainda que não exista significância estatística e, consequentemente não tenha sido corroborada a literatura, é perceptível que o escore de afinidade e de relação positiva total tende a ser mais baixo para estudantes classificados pelas professoras como pretos. Estudos com amostras maiores podem alterar esse resultado e, portanto, são recomendados.

Com relação à série, constatou-se que, no início da escolarização, o relacionamento professor-aluno tende ser melhor. Esse resultado pode estar associado com a variável idade, que se correlaciona negativamente com afinidade e relação positiva total com professor, e positivamente com conflito. Assim, futuras pesquisas devem considerar a defasagem idade-série, pois alunos defasados geralmente apresentam ou apresentaram alguma NEE.

Há uma produção científica significativa sobre a diversidade (cor/raça, sexo, idade, NEE etc.), mas comumente associada ao desempenho acadêmico. Assim, uma das principais contribuições do presente estudo foi ir além desse fator, atrelando as variáveis às interações entre os atores principais do ambiente escolar, docente e discente. Como evidenciado na revisão de literatura, tais relações são fundamentais para o desenvolvimento infantil, incluindo o desempenho acadêmico.

Reitera-se que há uma literatura expressiva sobre alunos em classes de reforço, repetentes e que deixam 
a escola (evasão), classificados como não-brancos e do sexo masculino (Carvalho, 2003, 2004a, 2004b, 2005; Henriques, 2002). Esses aspectos do rendimento acadêmico, provavelmente, influenciam e são influenciados pela relação docente-discente, que, por sua vez, como evidenciado nesta pesquisa, se associa às características demográficas e psicossociais dos estudantes.

Recomendam-se, dessa forma, pesquisas que associem as variáveis aqui estudadas - relação professor-aluno, sexo, NEE e cor/raça - ao desempenho acadêmico. É recomendável, também, considerar a homoafetividade no caso de sexo, isto é, não tratá-la de forma maniqueísta: masculino ou feminino. Há que se considerarem ademais outros fatores relacionados à diversidade em sala de aula, como, por exemplo, nível econômico e religião. Sugerem-se, ainda, investigações que comparem avaliações da relação professor-aluno efetuadas por discentes, docentes e observadores externos, sendo que nesse último caso pode se recorrer, por exemplo, à tecnologia por meio de filmagens.

O presente estudo possui limitações por considerar somente a percepção do professor, por empregar uma amostra limitada que não permitiu, por exemplo, comparar professores de diferentes cores/raças e dos sexos feminino e masculino, e por ter sido realizado somente em escolas da rede pública de ensino. Não obstante as limitações, a investigação pode ser considerada de alta relevância científica e social, uma vez que é mínima a literatura brasileira sobre a relação professor-aluno baseada em evidências empíricas, e os resultados obtidos têm implicações substanciais para a prática pedagógica. Por fim, há que se destacar que superar atitudes discriminatórias em relação a estudantes com NEE, pretos, do sexo masculino e que apresentam defasagem idade-série é fundamental para uma escola que pretende educar na diversidade e para a diversidade.

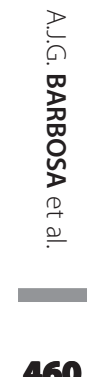

\section{Referências}

Baker, J. A. (2006). Contributions of teacher: child relationships to positive school adjustment during elementary school. Journal of School Psychology, 44, 211-229.

Barbosa, A. J., Campos, R. A., \& Valentim, T. A. (2007). Diversidade em sala de aula: um estudo exploratório sobre a relação professor-aluno [CD-ROM]. In Anais do $8^{\circ}$ Congresso Nacional de Psicologia Escolar e Educacional, São João Del Rei: Universidade Federal de São João Del Rei.
Birch, S. H., \& Ladd, G. W. (1997). The teacher-child relationship and children's early school adjustment. Journal of School Psychology, 35 (1), 61-79.

Boardman, A. G. (2004). Interactions between teachers and students with learning disabilities in general education classrooms. Unpublished doctoral dissertation, University of Texas, EUA.

Brasil. Ministério da Educação. Secretaria de Educação Especial. (2002). C327: Projeto Escola Viva: garantindo o acesso e permanência de todos os alunos na escola - alunos com necessidades educacionais especiais. Brasília: Autor.

Brok, P., \& Levy J. (2005). Teacher-student relationships in multicultural classes: reviewing the past, preparing the future. International Journal of Educational Research, 43, $72-88$.

Buyse, E., Verschueren, K., Doumen, S., Damme, J., \& Maes, F. (2007). Classroom problem behavior and teacher-child relationships in kindergarten: the moderating role of classroom climate. Journal of School Psychology, 46 (4). Retrieved May 8, 2007, from <http://www.sciencedirect. com>.

Carvalho, M.P. (2003). Sucesso e fracasso escolar: uma questão de gênero. Educação e Pesquisa, 29 (1), 185-193.

Carvalho, M. P. (2004a). O fracasso escolar de meninos e meninas: articulações entre gênero e cor/raça. Cadernos Pagu, 22, 247-290.

Carvalho, M.P. (2004b). Quem são os meninos que fracassam na escola? Cadernos de Pesquisa, 34 (121), 11-40.

Carvalho, M. (2005), Quem é negro, quem é branco: desempenho escolar e classificação racial de alunos. Revista Brasileira de Educação, 28, 77-96.

Coll C., \& Solé I. (1995). A interação professor/aluno no processo de aprendizagem. In C. Coll (Org.), Desenvolvimento psicológico e educação (Vol. 2, pp.281-297). Porto Alegre: Artes Médicas.

Dal'Igna, M. C. (2007). Desempenho escolar de meninos e meninas: há diferença? Educação em Revista, 46, 241-267.

Fraser, B. J., \& Walberg, H. J. (2005). Research on teacherstudent relationships and learning environments: context, retrospect and prospect. International Journal of Educational Research, 43, 103-109.

Henriques, R. (2002). Raça e gênero no sistema de ensino: os limites das políticas universalistas na educação. Brasília: Edições Unesco Brasil.

Katz, J., \& Mirenda, P. (2002). Including students with developmental disabilities in general education classrooms: social benefits. International Jornal of Special Education, 17 (2), 26-36.

Kesner, J. E., (2000) Teacher characteristics and the quality of child-teacher relationships. Journal of School Psychology, 28 (2), 133-149.

Munanga, K. (Org.) (2001). Superando o racismo na escola (2aed.) Brasília: Ministério da Educação.

Murray, C., Murray, K. M., \& Waas, G. A. (2008). Child and teacher reports of teacher-student relationships: 
concordance of perspectives and associations with school adjustment in urban kindergarten classrooms. Journal of Applied Developmental Psychology, 29, 49-61.

National Institute of Child Health and Human Development. (2005). NICHD study ofearly child care and youth development. Retrieved December 12, 2005, from <https://secc.rti.org>.

Organização das Nações Unidas para a Educação, a Ciência e a Cultura. (1994). Declaração de Salamanca sobre princípios, políticas e práticas na área das necessidades educativas especiais. Salamanca: Autor.

Patto, M. H. S. (1990). A produção do fracasso escolar: histórias de submissão e rebeldia. São Paulo: T.A.Queiroz.

Pianta, R. C. (2001). Student-teacher relationship scale. Odessa, FL: Psychological Assessment Resources.
Robertson, K., Chamberlain, B., \& Kasari, C. (2003). General education teachers'relationships with included children with autism. Journal of Autism and Developmental Disorders, 33 (2), 123-130.

Silva, S. C., \& Aranha, M. S. F. (2005). Interação entre professora e alunos em salas de aula com proposta pedagógica de educação inclusiva. Revista Brasileira de Educação Especial, 11 (3), 373-394.

Wubbels, T. (2005). Editorial: student perceptions of teacherstudent relationships in class. International Journal of Educational Research, 43, 1-5.

Recebido em: 19/10/2009

Versão final reapresentada em: 25/5/2011

Aprovado em: 1/6/2011 
